\title{
Autologous peripheral blood-derived stem cells transplantation for treatment of no- option angiitis-induced critical limb ischemia: 10-year management experience
}

Gang Fang ${ }^{1 \dagger}$, Xiaolang Jiang ${ }^{1 \dagger}$, Yuan Fang ${ }^{1}$, Tianyue Pan ${ }^{1}$, Hao Liu', Bichen Ren ${ }^{1}$, Zheng Wei ${ }^{2}$, Shiyang Gu², Bin Chen', Junhao Jiang ${ }^{1}$, Yun Shi ${ }^{1}$, Daqiao Guo ${ }^{1}$, Peng Liu' ${ }^{2}$, Weiguo Fu ${ }^{1,3^{*}}$ and Zhihui Dong ${ }^{1,3^{*}}$ (D)

\begin{abstract}
Background: Previous studies have demonstrated that no-option angiitis-induced critical limb ischemia (NO-AICLI) could be significantly improved by transplantation of peripheral blood-derived stem cells (PBDSCs). Additionally, a randomized controlled trial $(R C T)$ recently conducted by us suggested that peripheral blood-derived purified CD34+ cells (PCCs) were not inferior to non-purified peripheral blood mononuclear cells (PBMNCs) at limb salvage in treatment of NO-AICLI. However, most of these clinical trials whether RCT or single-arm studies were characterized with a small sample size and absence of long-term outcomes.

Methods: To analyze long-term clinical outcomes of PBDSCs transplantation for NO-AICLI, we reviewed clinical data of patients with NO-AICLI receiving PBDSCs transplantation at our center during the past decade. Meanwhile, we first compared the long-term safety and efficacy of intramuscular transplantation of PCCs versus PBMNCs in a sizable number of patients with NO-AICLI.

Results: From May 2009 to December 2019, a total of 160 patients with NO-AICLI patients were treated by PBDSCS transplantation (82 with PCCs, 78 with PBMNCs) at our center. Baseline characteristics between two groups were similar. Up to June 2020, the mean follow-up period was $46.6 \pm 35.3$ months. No critical adverse events were observed in either group. There was one death during the follow-up period. A total of eight major amputations occurred. The cumulative major amputation-free survival (MAFS) rate at 5 years after PBDSCs transplantation was $94.4 \%$, without difference between two groups $(P=.855)$. Wound healing, rest pain, pain-free walking time, ankle-brachial index, transcutaneous oxygen pressure, and quality of life (QoL) also significantly improved after PBDSCs transplantation. Conclusions: Autologous PBDSCs intramuscular transplantation could significantly decrease the major amputation rates and improve the QoL in patients with NO-AICLI. Long-term observation of a large sample of patients confirmed that the clinical benefits of PBDSCs transplantation were durable, without difference between the PCCs and PBMNCs groups.
\end{abstract}

Keywords: Stem cells transplantation, Critical limb ischemia, Thromboangiitis obliterans, Periphreal blood mononuclear cells, CD34+ cells, Limb salvage

\footnotetext{
*Correspondence: fu.weiguo@zs-hospital.sh.cn; dzh926@126.com

${ }^{\dagger}$ Gang Fang and Xiaolang Jiang contributed equally to this work.

'Department of Vascular Surgery, Zhongshan Hospital, Fudan University, Shanghai, China

Full list of author information is available at the end of the article
}

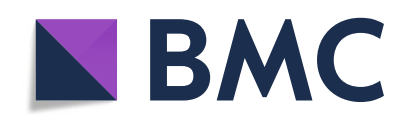

( ) The Author(s). 2020 Open Access This article is licensed under a Creative Commons Attribution 4.0 International License, which permits use, sharing, adaptation, distribution and reproduction in any medium or format, as long as you give appropriate credit to the original author(s) and the source, provide a link to the Creative Commons licence, and indicate if changes were made. The images or other third party material in this article are included in the article's Creative Commons licence, unless indicated otherwise in a credit line to the material. If material is not included in the article's Creative Commons licence and your intended use is not permitted by statutory regulation or exceeds the permitted use, you will need to obtain permission directly from the copyright holder. To view a copy of this licence, visit http://creativecommons.org/licenses/by/4.0/. The Creative Commons Public Domain Dedication waiver (http://creativecommons.org/publicdomain/zero/1.0/) applies to the data made available in this article, unless otherwise stated in a credit line to the data. 


\section{Background}

Critical limb ischemia (CLI), due to advanced peripheral artery disease (PAD), is characterized with high mortality and major amputation rates [1, 2]. Surgical and endovascular revascularization are the most common used techniques to improve symptoms in patients at this stage, especially for atherosclerosis (ASO)-induced CLI.

However, up to $20 \%$ of CLI patients are not eligible for revascularization (no-option CLI) $[3,4]$ and reported to have 6-month major amputation rates ranging from $10 \%$ to $40 \%$ $[2,5]$. Among patients with angiitis-induced CLI (AICLI), the proportion of "No-option" ones is much higher considering unfavorable anatomical conditions for traditional revascularization techniques and high re-occlusion rates after interventions due to the chronic autoimmune angiitis. Meanwhile, thromboangiitis obliterans (TAO) was the main cause of no-option AICLI (NO-AICLI). Compared with ASO, patients with TAO-induced CLI are remarkably younger and have much higher life expectations, posing a more urgent need for limb salvage and better quality of life (QoL) $[6,7]$. However, despite of the great development on endovascular treatment for limb ischemia in recent years, these innovative techniques and equipment are still based on the conventional theory of revascularization, which brings a fairly limited improvement on the poor prognosis of NO-AICLI. New treatment modalities are urgently needed for NO-AICLI.

Autologous stem cell therapy (SCT) aiming at promoting angiogenesis and neovascularization has recently been reported as a safe and effective way for treatment of nooption CLI (NO-CLI) [8-10]. Bone marrow-derived stem cells (BMDSCs) supposed to contain a higher concentration of endothelial progenitor cells was initially used [11-14]. Afterwards, given that obtainment of peripheral bloodderived stem cells (PBDSCs) is less invasive and more convenient, several clinical trials on PBDSCs transplantation for NO-CLI have been conducted and demonstrated comparable outcomes with BMDSCs [15-18]. Our previous pilot study indicated that granulocyte colony-stimulating factor (G-CSF)-mobilized peripheral blood-derived purified CD34+ cells (PCCs) transplantation could achieve favorable outcomes in NO-AICLI (a five-year major amputation-free survival rate (MAFS) of $88.9 \%$ ) [19, 20]. To investigate whether the angiogenesis induced by PCCs was impaired due to the cell loss during PCCs isolation, we then conducted a randomized controlled trial (RCT) to compare the non-purified peripheral blood mononuclear cells (PBMNCs) with PCCs in the treatment of NO-AICLI. Outcomes revealed that transplantation of both types of cells could significantly improve MAFS compared with conventional therapies and PCCs was not inferior to PBMNCs in the treatment of AICLI [21]. However, despite this, the sample size of this RCT is small and the follow-up period is too short to get long-term results.
The aim of this study was to analyze the short-term clinical efficacy and long-term clinical outcomes of SCT for NO-AICLI at our center during the past decade. Meanwhile, we compared the safety and efficacy of intramuscular transplantation of autologous peripheral blood-derived PCCs versus PBMNCs in a sizable number of patients with NO-AICLI.

\section{Methods}

\section{Study population}

From May 2009 to December 2019, patients with NOAICLI who received PBDSCs transplantation at our center were consecutively enrolled into this retrospective study. Inclusion criteria for PBDSCs transplantation comprised (1) patients aged 18 to 80 years; (2) presence of stenotic or occlusive lesions in the limb arteries, as confirmed by computed tomography angiography, magnetic resonance angiography, or digital subtraction angiography; (3) CLI with a Rutherford class of 4-5 that was anatomically unsuitable for open surgery or endovascular therapy; (4) no improvement for at least 3 months after open surgery or endovascular treatment, or no alleviation of rest pain after at least 1 month of conservative treatment including smoking cessation, regular drug therapy, dietary control, and exercise therapy; and (5) if present, an unhealing ulcer after at least 1 month of optimal care by a wound care physician and a nurse. Each enrolled patient should meet all of these criteria. Exclusion criteria included (1) serious health events occurred $<3$ months before admission, including but not limited to myocardial infarction, cerebral apoplexy, pulmonary embolism, severe hepatic dysfunction, and renal dysfunction or (2) contraindications for the administration of G-CSF. The study complied with the Declaration of Helsinki guidelines and was approved by the Committee for the protection of Human Subjects at Zhongshan Hospital, Fudan University. All patients participating in the study signed an informed consent document.

\section{Treatment procedures and follow-up protocol}

After admission, G-CSF (Neupogen; Amgen, Thousand Oaks, CA, USA) was injected subcutaneously to mobilize the bone marrow cells for 5 days. Meanwhile, enoxaparin (4000 IU/day) was administered daily to prevent hypercoagulability, and blood test was performed daily to test for white blood cell (WBC) and CD34+ cell counts. Suspension of PBMNCs was collected via leukapheresis (COM.TEC; Fresenius Hemocare GmbH, Bad Homburg, Germany) when the WBC count was elevated $>60 \times 10^{9} / \mathrm{L}$ or on the fifth day. And for patients in the PCCs group, the suspension was purified by a magnetic cell storing system (MiltenyiBiotec $\mathrm{GmbH}$, BergischGladbach, Germany) before transplantation. Leukocyte counting and flow cytometry was used to test the final cell product. The cell 
transplantation was performed by intramuscular injection under general anesthesia for the upper extremities or spinal anesthesia for the lower extremities. A total of 80 and 160 sites were each injected with $0.5 \mathrm{~mL}$ for patients in the PCCs and PBMNCs groups, respectively. And the injections were distributed in the calf and foot or the forearm and hand of the ischemic limbs evenly. And the final transplanted CD34+ cells were controlled ranging from $10^{5}$ to $10^{6}$ per kilogram body weight. All patients were followed once a month for the first 3 months, every 3 months for the rest of the year, and once a year afterwards. Aspirin (100 $\mathrm{mg} / \mathrm{d})$, cilostazol $(400 \mathrm{mg} / \mathrm{d})$, and anplag $(300 \mathrm{mg} / \mathrm{d})$ were administrated for at least 1 year. Major amputations (above the ankle) during the follow-up period and any adverse events related to the treatment procedure were recorded. Ulcer healing, confirmed by a clinician who observed and photographed the patients' limbs, and Rutherford classification were recorded at the baseline and each follow-up point. Wong-Baker faces pain rating scale (WBFPS), in which a score of 0 represents no pain and a score of 10 represents greatest pain, was used to evaluate the patients' rest pain in the absence of analgesic agents at the baseline and each follow-up point. The pain-free walking time (PFWT) at $2.5 \mathrm{~km} / \mathrm{h}$ and at a $10 \%$ incline on a treadmill was evaluated 3 and 6 months after transplantation and yearly afterwards. For patients who could not perform the test, the PFWP was recorded as 0 . Ankle-brachial index (ABI) and transcutaneous pressure of oxygen $\left(\mathrm{TcPO}_{2}\right)$ of the dorsum were also detected at each follow-up point, and the QoL was evaluated by 36-item Short Form Health Survey (SFHS-36) at the baseline and once a year after cell transplantation. Ophthalmoscopy was used to assess pathological angiogenesis in the retina at each follow-up point.

\section{Data collection}

Prospectively collected clinical data was retrospectively analyzed in the current study. The data included the demographic information, the etiology of the limb ischemia, the risk factors for peripheral artery and cardiovascular diseases, and previous surgical therapy. Treatment information including cell type, characteristics of cell products, and adverse events were also reviewed. Furthermore, the baseline and follow-up features of the treated limb were reviewed, including the Rutherford class, wound healing, $\mathrm{ABI}$, and $\mathrm{TcPO}_{2}$ of the dorsum. The WBFPS, PFWT, and QoL of the enrolled patients were also analyzed in this study.

The primary endpoint was the rate of freedom from major amputations of the treated limb. The secondary endpoints included all-cause death, the ulcer healing rate, WBFPS, and PFWT.

\section{Statistical analysis}

Continuous variables were presented as mean \pm standard deviation, and categorical variables were presented as frequencies and percentages. The efficacy parameters were analyzed by using a generalized estimating equation model with longitudinal analysis of data changing from the baseline to months $1,3,6,12,36$, and 60 . The MAFS was estimated with the Kaplan-Meier method, and differences in survival among the groups were analyzed with the log-rank test. The Wilcoxon signed-rank test was used to compare the QoL values at baseline and each follow-up examination. A $P$ value $<.05$ was considered to indicate a statistically significant difference. The statistical analyses were performed using SAS software, version 9.3 (SAS Institute, Cary, NY).

\section{Results \\ Study population}

From May 2009 to December 2019, a total of 172 patients with CLI received SCT at our center. Among them, 12 patients with ASO as their etiology were excluded from this study. Finally, 160 patients with NO-AICLI were enrolled in this study. According to the type of PBDSCs, these patients could be divided into two groups. Eightytwo patients received intramuscular transplantation of PCCs, while 78 patients were treated with PBMNCs.

Baseline patient characteristics are presented in Table 1. TAO was the most common (155/160, 96.9\%) cause of limb ischemia in enrolled patients. Patients with TAO were all male and most of them had high frequencies of smoking history. All of the patients presented NO-CLI in one limb, except for 4 patients who had more than 2 ischemic limbs, the most ischemic of which, those with $\mathrm{ABI}<0.4$, were included in the current study. Rutherford 5 patients accounted for $89.4 \%$ at enrollment. Most of patients underwent regular medical therapy and/or at least one type of revascularization techniques before PBDSCs transplantation. The baseline characteristics were similar between two cell groups.

Up to June 2020, the mean follow-up period was $46.6 \pm$ 35.3 months (range 6-132 months). There were eight major amputations during follow-up. One patient in the PCCs group was lost to follow-up at 2 months and one patient in the PBMNCs group died at 18 months. A total of 48 patients have completed the 5-year follow-up evaluation. The specific follow-up information is shown in Fig. 1.

\section{Quality of the cell products}

The mean final transplant volumes were $39.2 \mathrm{~mL}$ in the PCCs group and $85.4 \mathrm{~mL}$ in the PBMNCs group $(P<.001)$. The total WBC counts and concentrations were significantly higher in the PBMNCs group than in the PCCs group $(P<.001)$. There was no significant difference in CD34+ cell concentrations between two groups $(P=.843$, Table 2$)$. 
Table 1 Baseline characteristics of enrolled patients

\begin{tabular}{|c|c|c|c|c|}
\hline Characteristics & Total & PCCs (82) & PBMNCs (78) & $P$ \\
\hline Age, years & $41.2(11.2)$ & $40.6(10.5)$ & $41.8(11.8)$ & .610 \\
\hline Male, $n(\%)$ & $157(98.1)$ & $80(97.6)$ & 77 (96.3) & .990 \\
\hline $\mathrm{BMl}, \mathrm{kg} / \mathrm{m}^{2}$ & $23.2(3.7)$ & $23.5(3.5)$ & $22.9(3.8)$ & .820 \\
\hline \multicolumn{5}{|l|}{ Etiology } \\
\hline $\mathrm{TAO}, n(\%)$ & $155(96.9)$ & $79(96.3)$ & $76(97.4)$ & 1.000 \\
\hline Eosinophilia, n (\%) & $1(0.63)$ & $0(0)$ & $1(1.30)$ & .487 \\
\hline $\mathrm{SLE}, n(\%)$ & $3(1.88)$ & $2(2.4)$ & $1(1.3)$ & 1.000 \\
\hline Erythema nodosum, $n$ (\%) & $1(0.63)$ & $1(1.2)$ & $0(0)$ & 1.000 \\
\hline \multicolumn{5}{|l|}{ Comorbidities } \\
\hline Smoking, $n(\%)$ & $145(90.6)$ & $72(87.8)$ & $73(93.6)$ & .210 \\
\hline Hypertension, $n(\%)$ & $8(5.0)$ & $5(6.1)$ & $3(3.8)$ & .720 \\
\hline Type II diabetes mellitus, $n$ (\%) & $8(5.0)$ & $4(4.9)$ & $4(5.1)$ & .990 \\
\hline Hyperlipidemia, $n$ (\%) & $11(6.88)$ & $7(8.5)$ & $4(5.1)$ & .394 \\
\hline Coronary artery disease, $n(\%)$ & $3(1.88)$ & $2(2.4)$ & $1(1.3)$ & .990 \\
\hline \multicolumn{5}{|l|}{ Treated limbs } \\
\hline Upper/lower extremity, $n$ & $5 / 155$ & $3 / 79$ & $2 / 76$ & .990 \\
\hline Right/left, $n$ & $86 / 74$ & $44 / 38$ & $42 / 36$ & .989 \\
\hline Ulcer only, $n$ (\%) & 75 (46.9) & $34(41.5)$ & $41(52.6)$ & .160 \\
\hline Gangrene, $n(\%)$ & $70(43.8)$ & $37(4.1)$ & $33(42.3)$ & .720 \\
\hline \multicolumn{5}{|l|}{ Rutherford class } \\
\hline $4, n(\%)$ & $15(18.3)$ & $11(13.4)$ & $4(5.1)$ & .720 \\
\hline $5, n(\%)$ & 145 (90.6) & 71 (86.6) & $74(94.9)$ & .720 \\
\hline \multicolumn{5}{|l|}{ Medication history } \\
\hline Aspirin, n (\%) & $134(83.8)$ & $66(80.5)$ & $68(87.2)$ & .251 \\
\hline Clopidogrel, n (\%) & $18(11.3)$ & $10(12.2)$ & $8(11.2)$ & .698 \\
\hline Cilostazol, n (\%) & $61(38.1)$ & $32(39.0)$ & $29(37.2)$ & .810 \\
\hline Prostaglandins, $n(\%)$ & $124(77.5)$ & $61(74.4)$ & $63(80.8)$ & .334 \\
\hline Warfarin, n (\%) & $6(3.8)$ & $4(4.9)$ & $2(2.6)$ & .682 \\
\hline Rivaroxaban, $n$ (\%) & $5(3.1)$ & $2(2.4)$ & $3(3.8)$ & .676 \\
\hline \multicolumn{5}{|l|}{ Surgical history } \\
\hline Bypass, $n(\%)$ & 18 (11.3) & $11(13.4)$ & $7(9.0)$ & .374 \\
\hline Endarterectomy, n (\%) & $5(3.1)$ & $3(3.7)$ & $2(2.6)$ & 1.000 \\
\hline PTA, $n(\%)$ & $42(26.3)$ & $20(24.2)$ & $22(28.2)$ & .584 \\
\hline Stenting, $n(\%)$ & $16(10.0)$ & $8(9.8)$ & $8(10.3)$ & .916 \\
\hline Thrombolysis, n (\%) & $52(32.5)$ & $28(34.1)$ & $24(30.8)$ & .648 \\
\hline Sympathectomy, n (\%) & $7(4.4)$ & $2(2.4)$ & $5(6.4)$ & .268 \\
\hline Surgical thrombectomy, $n$ (\%) & $22(13.8)$ & $12(14.6)$ & $10(12.8)$ & .739 \\
\hline Excimer laser thrombectomy, $n(\%)$ & $7(4.4)$ & $2(2.4)$ & $5(6.4)$ & .268 \\
\hline
\end{tabular}

PCCs purified CD34+ cells, PBMNCs peripheral blood mononuclear cells, BMI body mass index, TAO thromboangiitis obliterans, SLE systemic lupus erythematosus, PTA percutaneous transluminal angioplasty

\section{Safety evaluation}

There were no critical adverse events during the treatment and follow-up period. The counts of WBC decreased to normal level within 1 week in all patients after transplantation. Fifteen patients suffered adverse events during the mobilization period, including 1 patient with slight fever, 3 with back pain, 2 with transient headache, and 2 with pruritus in the PBMNCs group and 3 patients with slight fever, 2 with back pain, and 2 with pruritus in the PCCs group. All of them completely recovered within 2 weeks 


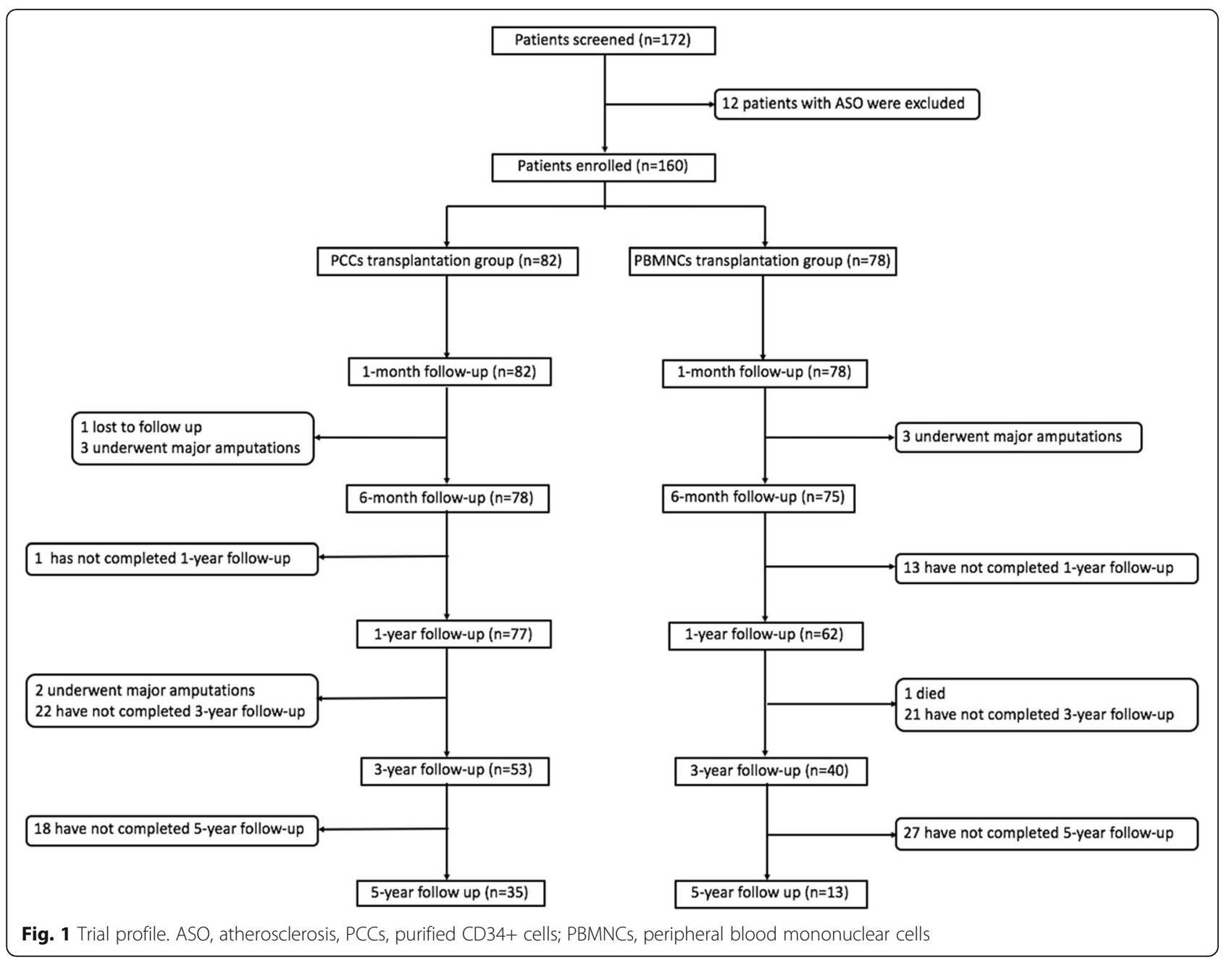

after transplantation. Pathological retinal angiogenesis was not observed during the follow-up.

\section{All-cause death and major amputations}

There was one death during the follow-up period. One patient in the PBMNCs group died at 18 months after SCT. The death was identified as not related to the study interventions. A total of eight major amputations occurred within the mean follow-up period of $46.6 \pm 35.3$ months. There were five major amputations in the PCCs group: two occurred at 3

Table 2 Characteristics of the cell product

\begin{tabular}{llll}
\hline Characteristics & PCCs(82) & PBMNCs(78) & $\boldsymbol{P}$ \\
\hline Final volume, $\mathrm{ml}$ & $39.2(1.3)$ & $85.4(22.7)$ & $<.001$ \\
Total WBC count, $\times 10^{6}$ & $53.1(25.6)$ & $21,400(11300)$ & $<.001$ \\
WBC concentration, $\times 10^{9} / \mathrm{L}$ & $1.53(0.72)$ & $249(121)$ & $<.001$ \\
CD34+ cell concentration, $\times 10^{8} / \mathrm{L}$ & $8.15(4.23)$ & $8.24(4.11)$ & .843 \\
CD34+ cells/WBCs, \% & $65(23)$ & $0.33(0.15)$ & $<.001$ \\
\hline
\end{tabular}

PCCs purified CD34+ cells, PBMNCs peripheral blood mononuclear cells, WBCs white blood cells months, the remaining three amputations at 5, 24, and 30 months, respectively. Three major amputations occurred in the PBMNCs group at 1, 2, and 3 months, respectively. The cumulative MAFS rate at 5 years after PBDSCs transplantation was $94.4 \%$. The 5 -year MAFS rates were $93.9 \%$ in the PCCs group and $94.9 \%$ in the PBMNCs group $(P=.855$, Fig. 2). When evaluating the major amputation rate by Rutherford classification in all patients, all major amputations occurred in Rutherford 5 patients, no enrolled Rutherford 4 patients underwent any major amputations. However, the difference was not statistically significant $(5.5 \%$ vs $0, P=1.0)$.

\section{Efficacy evaluation}

There were $71(86.6 \%)$ and 74 (93.7\%) patients with tissue loss in the PCCs and PBMNCs group, respectively. A total of 140 patients with tissue loss completed a 6-month follow-up (Fig. 3). Complete wound healing at 6 months was observed in over $60 \%$ of patients. In patients completing the 5-year follow-up, complete wound healing occurred in all 47 patients with tissue loss at enrollment, without difference between the two groups. Rutherford stage also 

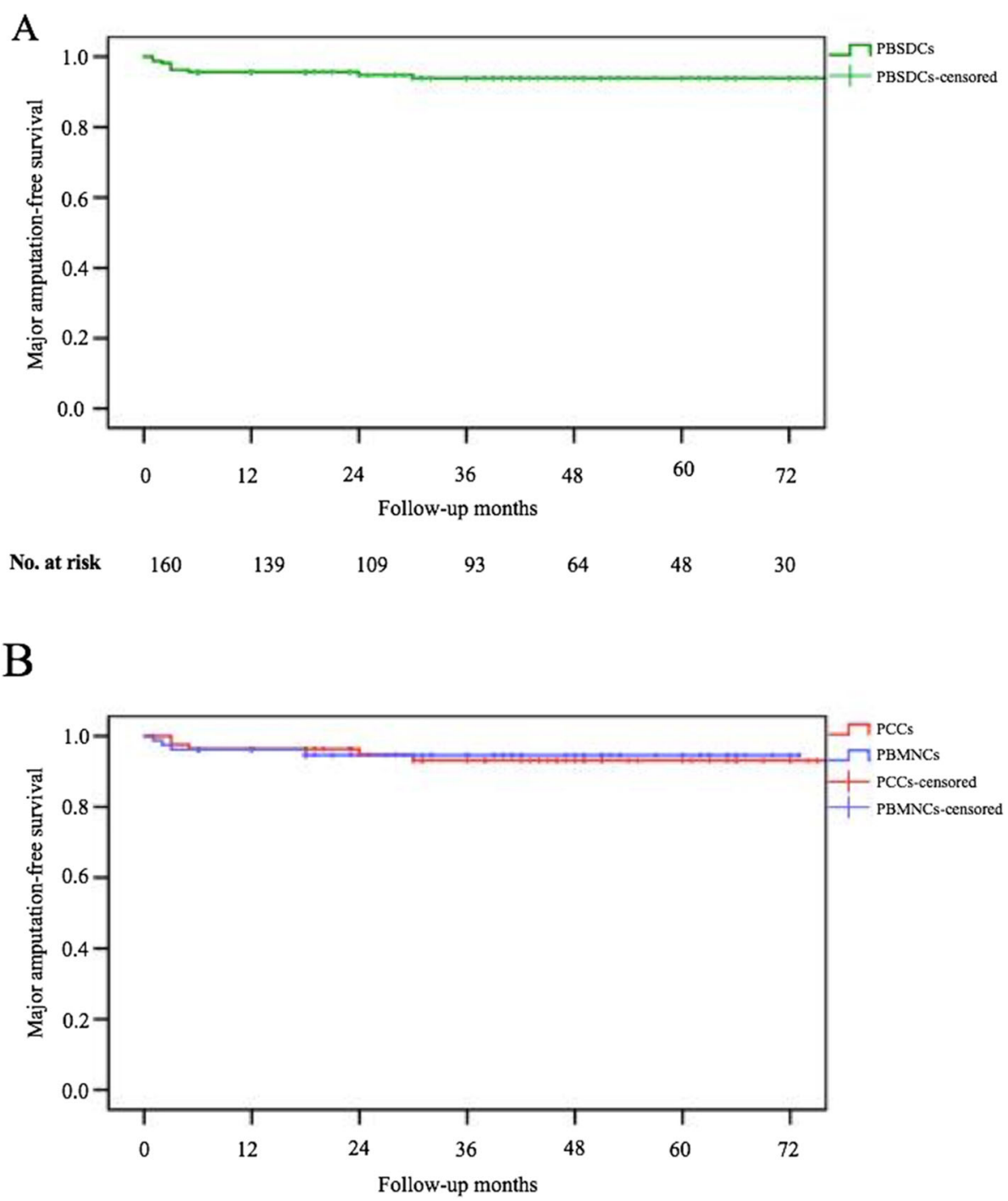

No. at risk

$\begin{array}{lccccccc}\text { PCCs } & 82 & 77 & 61 & 53 & 42 & 35 & 28 \\ \text { PBMnCs } & 78 & 62 & 48 & 40 & 22 & 13 & 2\end{array}$

Fig. 2 Kaplan-Meier analysis of major amputation-free sunvival rates after PBDSCs transplantation (a). Kaplan-Meier analysis of major amputation-free survival rates for the PCCs versus PBMNCs groups (b). PBDSCs, peripheral blood-derived stem cells; PCCs, purified CD34+ cells; PBMNCs, peripheral blood mononuclear cells

gradually improved in both groups after SCT. All enrolled patients were defined as Rutherford 4 or 5 class of limb ischemia. After a 6 -month follow-up, approximately $58 \%$ of patients had an obvious improvement on Rutherford stage to non-CLI. Notably, the proportion of non-CLI in patients completing 3-year follow-up reached over $93 \%$ and persisted till the 5-year follow-up, without difference between the two groups (Table 3).

The WBFPS and PFWT values after SCT gradually improved and this improvement persisted till 5 years. The mean values of WBFPS and PFWT were significantly better at each follow-up visit compared with baseline measurements. No difference was observed in both two parameters at each follow-up examination between the PCCs and PBMNCs groups except that the WBFPS values at 1 and 6 months were significantly lower in the PCCs group (Fig. 4).

Regarding to perfusion evaluating parameters, mean $\mathrm{ABI}$ and $\mathrm{TcPO}_{2}$ values were comparable between the two groups before treatment, and they improved significantly at each follow-up visit compared with the baseline. In addition, no difference in $\mathrm{ABI}$ and $\mathrm{TcPO}_{2}$ was observed between the PCCs and PBMNCs groups before and after SCT (Fig. 4). 

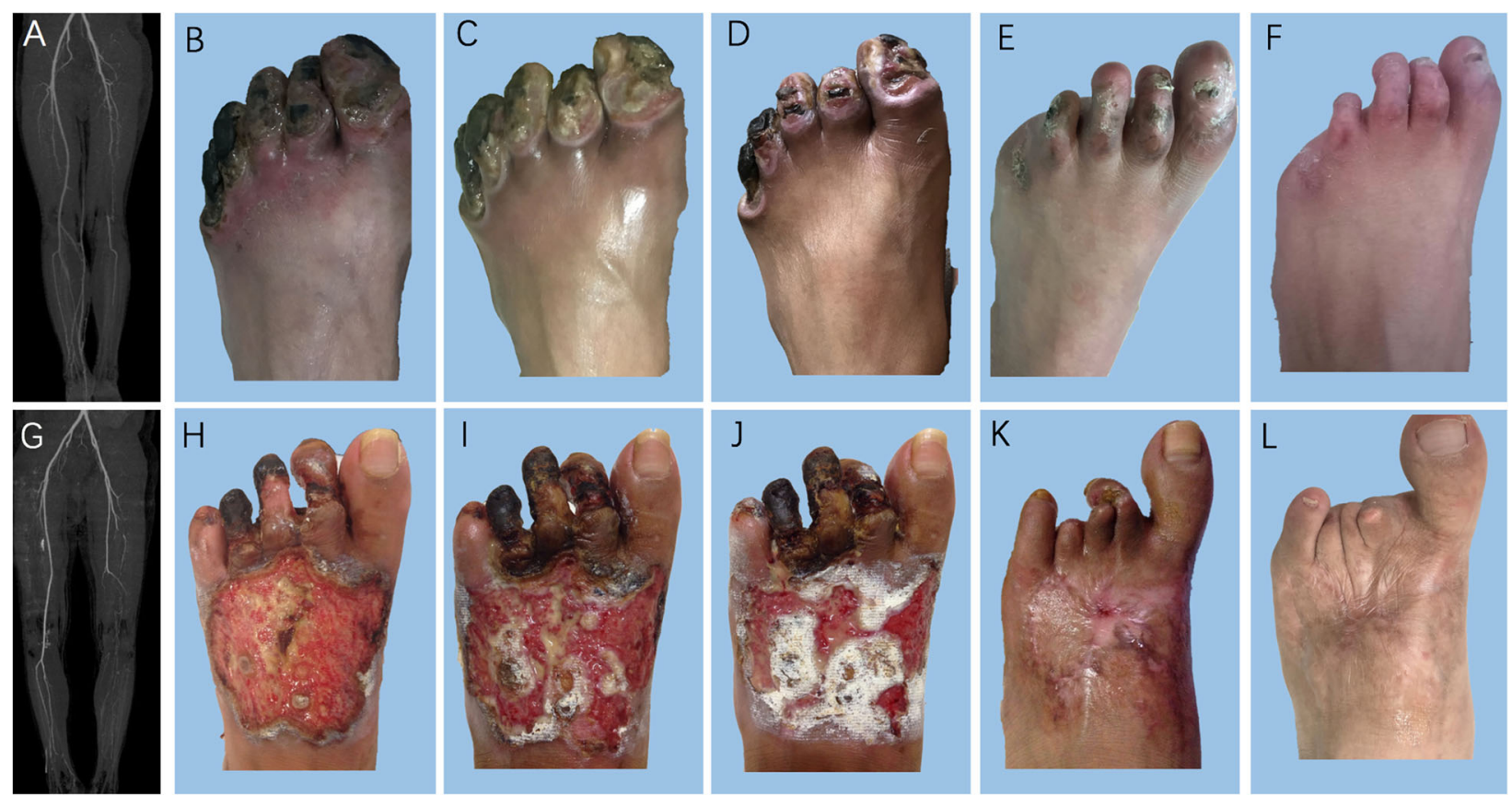

Fig. 3 Wound healing in the PCCs and PBMNCs groups. In a 37-year-old male with TAO (a-f), preoperative CTA showed artery occlusion on the left lower extremity with the occlusion level at the orifice of the superficial femoral artery (a). The patient had gangrene and ulcers on his left toes before PCCs transplantation (b). Wound was gradually healing at 1 (c), 3 (d), and 6 (e) months after PCCs transplantation and complete wound healing was observed at 12 months (f). In a 23-year-old male with TAO ( $(\mathbf{g}-\mathbf{l})$, preoperative CTA showed artery occlusion on the left lower extremity with the occlusion level at the distal superficial femoral artery (a). The patient had gangrene on his left toes and a large ulcer on the dorsum of his left foot before PBMNCs transplantation (b). Wound was gradually healing at 1 (c), 3 (d), and 6 (e) months after PBMNCs transplantation and complete wound healing was observed at 12 months (f). PCCs, purified CD34+ cells; PBMNCs, peripheral blood mononuclear cells, TAO, thromboangiitis obliterans

Table 3 Wound healing, and Rutherford class $0-3$ at 1, 6, 12, 36, and 60 months

\begin{tabular}{lllll}
\hline Outcome & Total & PCCs & PBMNCs & $P$ \\
\hline Complete wound healing, $n(\%)$ & & & \\
At enrollment & $0 / 145$ & $0 / 71$ & $0 / 74$ & 1.000 \\
At 1 months & $13 / 145$ & $6 / 71$ & $7 / 74$ & .846 \\
At 6 months & $85 / 140$ & $40 / 69$ & $45 / 71$ & .512 \\
At 12 months & $111 / 128$ & $58 / 68$ & $53 / 60$ & .613 \\
At 36 months & $86 / 90$ & $50 / 51$ & $36 / 39$ & .880 \\
At 60 months & $47 / 47$ & $34 / 34$ & $13 / 13$ & .292 \\
Rutherford class 0-3, $n(\%)$ & & & \\
At enrollment & $0 / 160$ & $0 / 82$ & $0 / 78$ & 1.000 \\
At 1 month & $19 / 160$ & $10 / 82$ & $9 / 78$ & .898 \\
At 6 months & $89 / 153$ & $43 / 78$ & $46 / 75$ & .437 \\
At 12 months & $120 / 139$ & $64 / 77$ & $56 / 62$ & .219 \\
At 36 months & $87 / 93$ & $50 / 53$ & $37 / 40$ & 1.000 \\
At 60 months & $47 / 48$ & $34 / 35$ & $13 / 13$ & 1.000 \\
\hline PCCs purified CD34+ cells, PBMNCs peripheral blood mononuclear cells &
\end{tabular}

PCCs purified CD34+ cells, PBMNCs peripheral blood mononuclear cells
QoL scores gradually increased after SCT and persisted till 5 years. There was a significant improvement in all eight sections of SFHS-36 at 1, 3, and 5 years compared with the baseline, without difference between the PCCs and PBMNCs groups (Fig. 5).

\section{Discussion}

Although not as common as ASO-induced CLI, AICLI still represents an important subgroup of advanced PAD. Meanwhile, AICLI is characterized with higher incidence in East Asians, much lower onset age, and a higher proportion of no-option ones, which causes a tricky dilemma that conventional revascularization modalities hardly work in these patients with higher levels of expectation of limb salvage, especially in China where there is a large population of patients with AICLI [22, 23]. This is one of the reasons why we selected patients with NO-AICLI as our treatment subjects by SCT. Several previous studies have demonstrated PBDSCs transplantation presented similar outcomes with BMDSCs on limb salvage [18, 24, 25]. However, the sample size was relatively small whether in RCT or single-arm studies [26-29]. To our knowledge, the current series represents the largest number of patients with AICLI treated by PBDSCs transplantation in a single center. Meanwhile, though not designed as an RCT, 


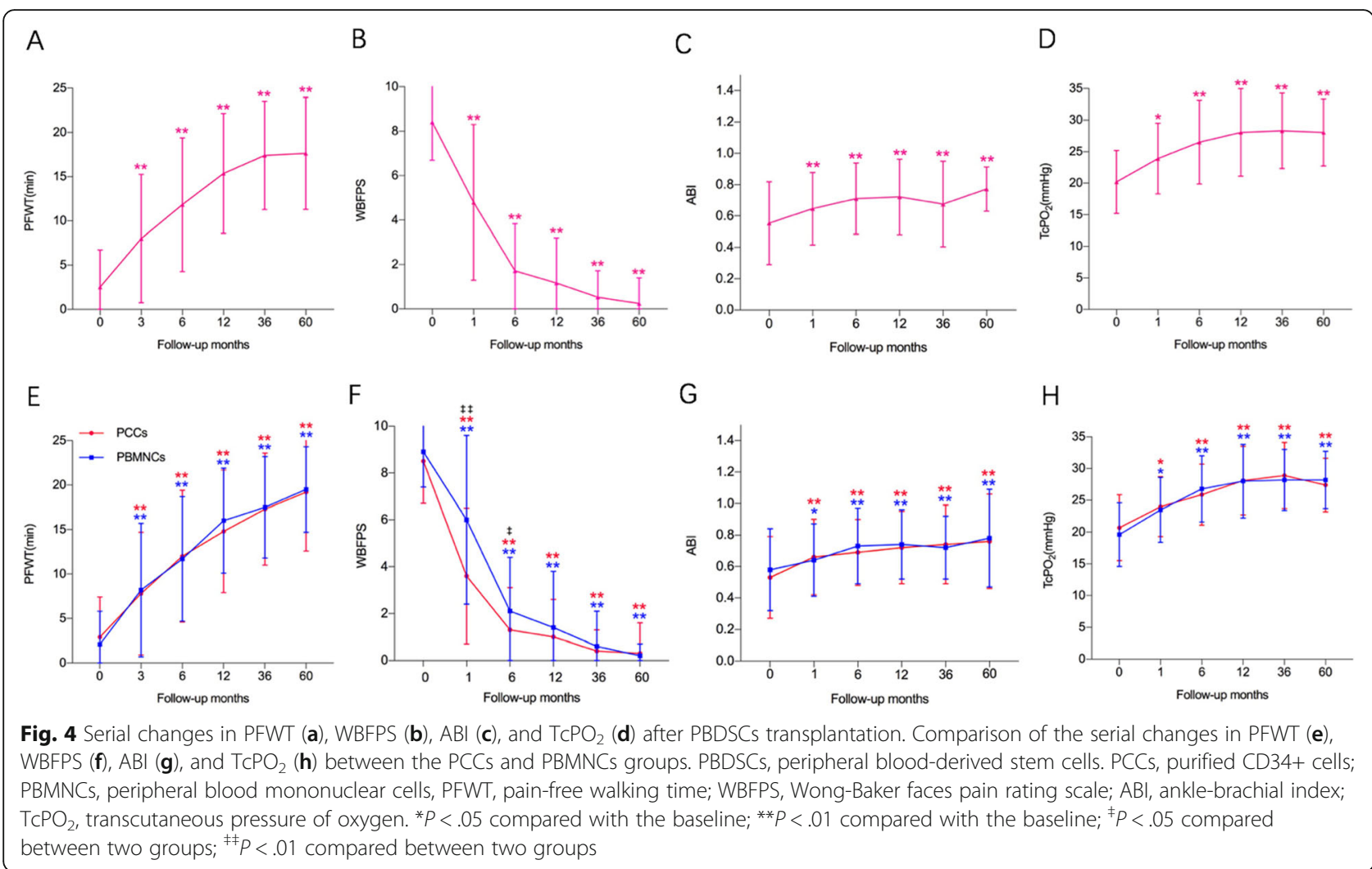

the baseline characteristics of patients in PCCs and PBMNCs groups are similar in the current retrospective study, which therefore ensures the comparability of outcomes after transplantation of two types of PBDSCs. This study shows that autologous PBDSCs intramuscular transplantation was effective in improving symptoms at an early stage and the clinical efficacy persisted over the long term, without any serious adverse events. A significant improvement on clinical and hemodynamic outcomes was observed in both treatment groups without any significant difference between the groups, validating that the clinical efficacy of PCCs was not impaired due to the cell loss during PCCs isolation. Based on the outcomes of the current study and the fact that CD34+ cells are the key component of endothelial progenitor cells-enriched fraction of PBMNCs, we believe that CD34+ cells play a predominant role in PBMNCs transplantation for NO-AICLI. Despite this, the PCCs group with obviously higher purity of CD34+ cells did not present better clinical efficacy compared with the PBMNCs group. Hence, it remains to be investigated whether the therapeutic effects of PBDSCs transplantation could be further improved.

Several previous clinical studies have demonstrated the beneficial effect of SCT on limb salvage and ulcer healing in NO-AICLI compared with placebo intervention $[20,21,30-32]$. More recent data reported by $\mathrm{Gu}$ et al. suggested that the 10-year amputation-free survival was
85.3\% in patients with TAO treated by BMMNCs, similar with the long-term MAFS in this study [33]. However, such favorable limb salvage rates were not observed in ASO-induced NO-CLI by SCT. More recent studies observed that patients with NO-AICLI benefit much more from SCT than those with ASO-induced NO-CLI [19, 34]. The JUVENTAS trial, which was deemed as a well-designed double-blinded, placebocontrolled clinical trial with a relatively larger sample size, enrolled patients with ASO-induced NO-ACL as the majority of the subjects [35]. Outcomes of this study indicated autologous BMDSCs repetitive intra-vascular transplantation had no effect on the primary outcome of major amputation rates compared with the placebo group (19\% vs 13\%) [36]. The failure in validating the beneficial effects of BMDSCs administration in the JUVENTAS trial was partly attributed to the high proportion of enrolled aged patients with a high systemic atherosclerotic burden and prevalence of cardiovascular disease. Moreover, our recent published study has reported that age $\geq 50$ years and arterial occlusion above the knee/elbow combined with blood fibrinogen, $\mathrm{TcPO}_{2}$, and the total transplanted CD34+ cell count were independent prognostic factors of the responders to PBDSCs -based therapeutic angiogenesis for NO-CLI, which suggested that ASO-induced NO-CLI characterized with an advanced age and a higher arterial occlusion plane was 


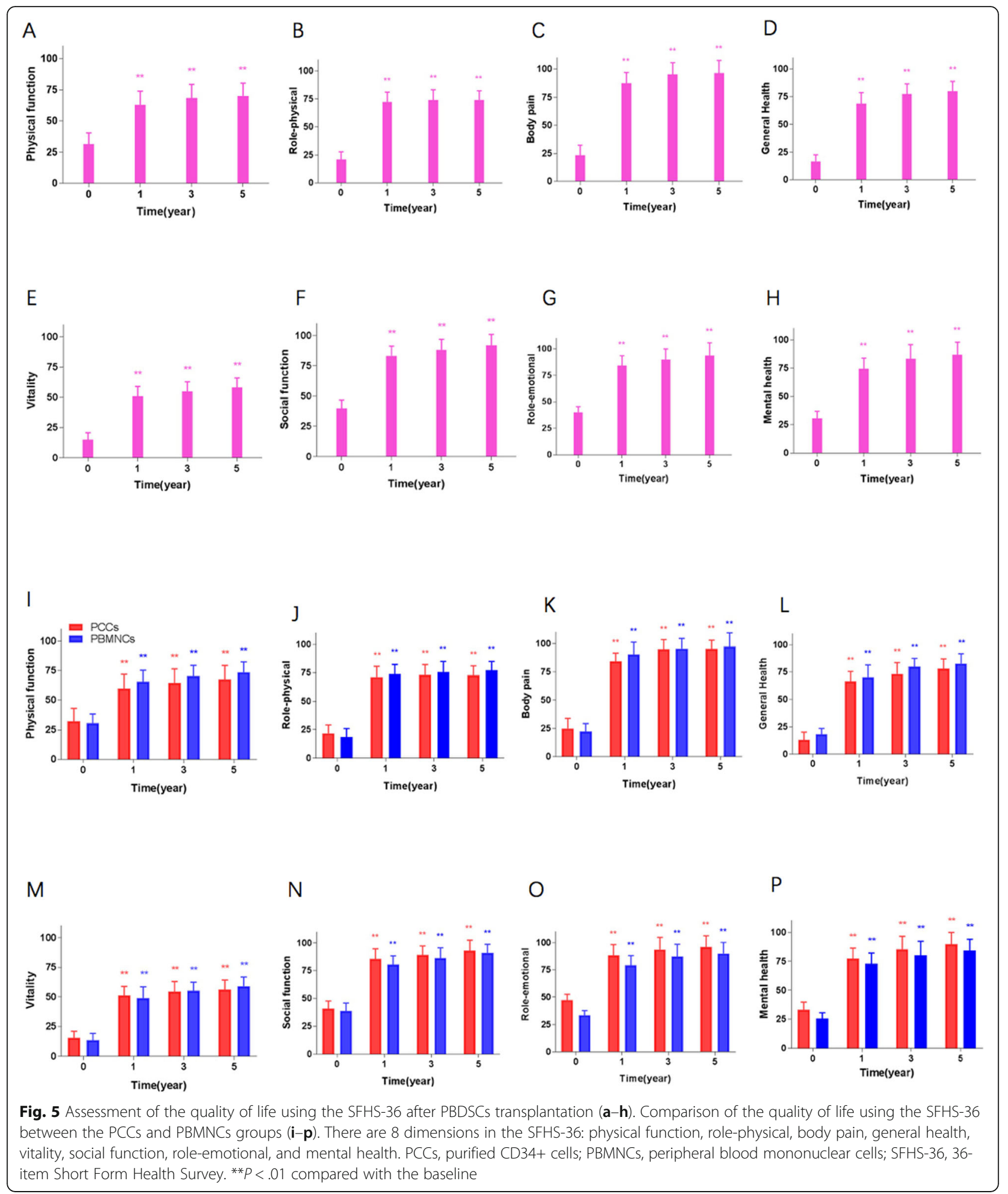

less likely to benefit from SCT [37]. Therefore, despite that the first published clinical trial on SCT for NO-CLI conducted by Tateishi-Yuyama et al. enrolled patients with ASO as the major group of subjects, NO-AICLI seemed to be the better candidate in advanced PAD for SCT according to published data.

An interesting observation in the current study was that all major amputations occurred in Rutherford 5 
patients. Despite equally classified into CLI and enrolled as an important subgroup in the present study, Rutherford 4 patients without tissue loss were at a much lower risk of major amputations after SCT than Rutherford 5 patients. Similar observations have been reported in recent years. Benoit et al. conducted a prospective doubleblinded RCT (2:1 therapy to control) of 48 patients with NO-CLI treated with BMDSCs and found that amputation rates in patients with tissue loss were significantly higher than patients with rest pain only $(46.7 \%$ vs $5.6 \%$, $P=$.0029) [38]. A further meta-analysis of the literature was performed and confirmed a difference in amputation rates between patients with tissue loss and rest pain [38]. These outcomes suggested that the number of enrolled Rutherford 4 patients should be limited in a clinical trial regarding SCT for NO-CLI if the primary endpoint of the trial is major amputation rate or MAFS, considering that the much lower major amputation rates in Rutherford 4 patients might dilute the event rate in the overall enrolled population making it difficult to assess the clinical efficacy. In addition, given that the much more favorable outcomes of SCT for AICLI compared with traditional modalities and the significant difference in limb salvage after SCT between patients with rest pain and tissue loss, we highly recommend to use PBDSCs transplantation as the first-choice therapy in patients with angiitis-induced Rutherford 4 class limb ischemia, avoiding that the possibility of progressing into tissue loss during the phase of traditional revascularization treatment which seldom works in AICLI.

As described above, patients with tissue loss correlates a relatively poorer prognosis than patients with rest pain after SCT. Despite this, in the current study, the major amputation rates of $5.5 \%$ in patients with tissue loss were still rather encouraging given that these patients were at a huge risk of major amputations with traditional therapies. SCT is characterized with a lower and slow-acting improvement of limb perfusion. Therefore, cell therapy was considered challenging to reverse more acute, diffuse, and critical ischemia. For this reason, Rutherford 6 patients with major tissue loss were excluded from the current study. Almost all clinical trials on SCT for CLI categorized the extent of tissue loss by the Rutherford classification. In studies containing Rutherford 6 patients, Madaric et al. reported an association between Rutherford 6 limb ischemia and a negative therapeutic outcome of SCT, which was in consistent with the results of the PROVASA trial where Rutherford 6 patients at baseline did not benefit from SCT $[39,40]$. However, as reported by Mills et al., the Rutherford classification of lower extremity ischemia lacks sufficient detail such like depth of the wound and presence and severity of infection with respect to wound categorization, failing to achieve more precise stratification among patients with tissue loss to aid in selection of the best therapy [41]. The WIFI classification has been regarded as a more objective and accurate classification of the ischemia-induced lower extremity wound based on the degree of ischemia, wound extent, gangrene, and infection, creating a more reasonable gradient of limb perfusion required for wound healing [41]. There is a great potential for application of the WIFI classification in future clinical trials on SCT, as more accurate and detailed stratification of patients with tissue loss would yield a better platform for performing more meaningful comparisons, thereby determining the optimal target population that could benefit from SCT among patients with tissue loss.

The mechanism of improvement of limb ischemia after SCT remains to be investigated. Unlike with mechanical revascularization of relatively larger arteries in conventional open and endovascular interventions, the mechanism of SCT is more complicated and mainly based on angiogenesis by differentiation of transplanted stem cells into endothelial lineage cells composing the structure of microcirculation [3, 42-44]. Paracrine action and antiinflammation effects have also recently been demonstrated as important roles in SCT [45-47]. Hemodynamic parameters like $\mathrm{ABI}$ and $\mathrm{TcPO}_{2}$ were commonly used in evaluating lower limb perfusion and regarded as effective noninvasive modalities correlating well with clinical severity parameters after revascularization interventions [48]. Considering that the functional mechanism of cell therapy is totally different from revascularization modalities, application of conventional hemodynamic parameters, especially ABI which reflects the blood flow in relatively large size of artery, in predicting the clinical trend after SCT remains to be studied $[26,37,38]$. Fujita et al. observed that the time course of the improvement on clinical parameters were not parallel with functional parameters after SCT. It was also reported that the change of ABI after SCT was rather limited despite the great improvement of the clinical status [49]. Similarly, though the mean $\mathrm{ABI}$ and $\mathrm{TcPO}_{2}$ values in the current study significantly increased compared with the baseline, whereas the degree of change is still modest compared with the dramatic improvement of ischemic symptoms. These results suggested that clinical severity parameters including ulcer healing and Rutherford class might be more valid endpoints for assessing the treatment efficacy than hemodynamic parameters in trials investigating SCT for CLI at least for now. Hence, with SCT more commonly used in limb ischemia, apart from continuing exploring the mechanism of perfusion restoration after SCT, it is also of great significance to find a safe, fast, and easily repeatable hemodynamic testing modality more appropriate for cell therapy to accurately monitor the change of lower extremity perfusion, thereby allowing vascular specialists to refine our current understanding of the disease process while assessing wound healing potential, optimizing the clinical decision making, and improving outcomes after SCT. 
The advantages of the present study include its welldesigned inclusion criteria for SCT, a larger sample size, comparability of both groups of patients in terms of their baseline characteristics, prospective follow-up, and comprehensive assessments. The main limitation of this study is that the analysis was retrospectively in nature although the data were collected prospectively. In addition, while the mean follow-up period of enrolled patients was relatively longer, the proportion of patients completing a 5year follow-up was small in the PBMNCs group.

\section{Conclusions}

Autologous PBDSCs intramuscular transplantation could significantly decrease the major amputation rates and improve the QoL in patients with NO-AICLI. Long-term observation of a large sample of patients confirmed that the clinical benefits of PBDSCs transplantation were durable, without difference between the PCCs and PBMNCs groups.

\section{Abbreviations}

SCT: Stem cell therapy; PBDSCs: Peripheral blood-derived stem cells; PBMNCs: Peripheral blood mononuclear cells; PCCs: Purified CD34+ cells; NOAICLI: No-option angiitis-induced critical limb ischemia; AICLI: Angiitisinduced critical limb ischemia

\section{Acknowledgements}

Not applicable

\section{Authors' contributions}

FG and JX designed the study, wrote the manuscript, and analyzed the patient data. DZ and FW designed the study and wrote the manuscript. FY, $P T, L H, R B, W Z, G S, C B, J J, S Y, G D$, and LP wrote the manuscript and collected the data of the patients. All authors read and approved the final manuscript.

\section{Funding}

This research was supported by the China National Natural Science Funds (grant No. 81970407), Training program for outstanding academic leaders of Shanghai health and family planning system (Hundred Talent Program, grant No. 2018BR40); the Program of Shanghai Academic Research Leader (grant No. 19XD1401200); and the Training Project for "Future Star" Doctor of Fudan University (2019).

\section{Availability of data and materials}

The datasets used and analyzed during the current study are available from the corresponding author on reasonable request.

\section{Ethics approval and consent to participate}

The study design was approved by the Ethics Committee of Zhongshan Hospital, Fudan University, Shanghai, China. All included patients were informed about the nature of the study and gave their written informed consent.

\section{Consent for publication}

All patients signed a consent form for their data to be used for research or publication.

\section{Competing interests}

The authors declare that they have no competing interests.

\section{Author details}

'Department of Vascular Surgery, Zhongshan Hospital, Fudan University, Shanghai, China. ${ }^{2}$ Department of Hematology, Zhongshan Hospital, Fudan University, Shanghai, China. ${ }^{3}$ Department of Vascular Surgery, Institute of
Vascular Surgery, Zhongshan Hospital, Fudan University, 180 Fenglin Road, Shanghai 200032, China

Received: 20 August 2020 Accepted: 19 October 2020

Published online: 28 October 2020

\section{References}

1. Conte MS, Bradbury AW, Kolh P, et al. Global vascular guidelines on the management of chronic limb-threatening ischemia. Eur J Vasc Endovasc Surg. 2019;58:S1-S109.e33.

2. Norgren L, Hiatt WR, Dormandy JA, Nehler MR, Harris KA, Fowkes FG. Intersociety consensus for the management of peripheral arterial disease (TASC II). J Vasc Surg. 2007;45(Suppl S):S5-67.

3. Attanasio $S$, Snell J. Therapeutic angiogenesis in the management of critical limb ischemia: current concepts and review. Cardiol Rev. 2009:17:115-20.

4. Lawall $H$, Bramlage $P$, Amann B. Treatment of peripheral arterial disease using stem and progenitor cell therapy. J Vasc Surg. 2011;53:445-53.

5. Powell RJ. Update on clinical trials evaluating the effect of biologic therapy in patients with critical limb ischemia. J Vasc Surg. 2012;56:264-6.

6. Klein-Weigel PF, Richter JG. Thromboangiitis obliterans (Buerger's disease). VASA. 2014:43:337-46.

7. Vijayakumar A, Tiwari R, Kumar PV. Thromboangiitis obliterans (Buerger's disease)-current practices. Int J Inflamm. 2013;2013:156905.

8. Tateishi-Yuyama E, Matsubara H, Murohara T, et al. Therapeutic angiogenesis for patients with limb ischaemia by autologous transplantation of bonemarrow cells: a pilot study and a randomised controlled trial. Lancet. 2002; 360:427-35.

9. Lasala GP, Silva JA, Minguell JJ. Therapeutic angiogenesis in patients with severe limb ischemia by transplantation of a combination stem cell product. J Thorac Cardiovasc Surg. 2012;144:377-82.

10. Powell RJ. Update on biological therapies for critical limb ischemia. Cardiol Clin. 2011;29:411-7.

11. Alev C, li M, Asahara T. Endothelial progenitor cells: a novel tool for the therapy of ischemic diseases. Antioxid Redox Signal. 2011;15:949-65.

12. Ismail AM, Abdou SM, Aty HA, et al. Autologous transplantation of CD34(+) bone marrow derived mononuclear cells in management of nonreconstructable critical lower limb ischemia. Cytotechnology. 2016;68:77181

13. Dubsky M, Jirkovska A, Bem $R$, et al. Treatment of critical limb ischemia and diabetic foot disease by the use of autologous stem cells. Vnitr Lek. 2011;57: 451-5.

14. Smadja DM, Duong-van-Huyen JP, Dal Cortivo L, et al. Early endothelial progenitor cells in bone marrow are a biomarker of cell therapy success in patients with critical limb ischemia. Cytotherapy. 2012;14:232-9.

15. Inaba S, Egashira K, Komori K. Peripheral-blood or bone-marrow mononuclear cells for therapeutic angiogenesis? Lancet. 2002;360:2083 author reply 4.

16. Canizo MC, Lozano F, Gonzalez-Porras JR, et al. Peripheral endothelial progenitor cells (CD133 +) for therapeutic vasculogenesis in a patient with critical limb ischemia. One year follow-up. Cytotherapy. 2007:9:99-102.

17. Ozturk A, Kucukardali Y, Tangi F, et al. Therapeutical potential of autologous peripheral blood mononuclear cell transplantation in patients with type 2 diabetic critical limb ischemia. J Diabetes Complicat. 2012;26:29-33.

18. Dubsky M, Jirkovska A, Bem R, et al. Both autologous bone marrow mononuclear cell and peripheral blood progenitor cell therapies similarly improve ischaemia in patients with diabetic foot in comparison with control treatment. Diabetes Metab Res Rev. 2013;29:369-76.

19. Dong Z, Chen B, Fu W, et al. Transplantation of purified CD34+ cells in the treatment of critical limb ischemia. J Vasc Surg. 2013:58:404-11.e3.

20. Fang $Y$, Wei $Z$, Chen B, et al. A five-year study of the efficacy of purified CD34+ cell therapy for angiitis-induced no-option critical limb ischemia. Stem Cells Transl Med. 2018;7:583-90.

21. Dong Z, Pan T, Fang Y, et al. Purified CD34(+) cells versus peripheral blood mononuclear cells in the treatment of angiitis-induced no-option critical limb ischaemia: 12-month results of a prospective randomised singleblinded non-inferiority trial. EBioMedicine. 2018;35:46-57.

22. Li MD, Wang YF, Yang MW, Hong FF, Yang SL. Risk factors, mechanisms and treatments of thromboangiitis obliterans: an overview of recent research. Curr Med Chem. 2019.

23. Małecki $\mathrm{R}$, Zdrojowy $\mathrm{K}$, Adamiec $\mathrm{R}$. Thromboangiitis obliterans in the $21 \mathrm{st}$ century--a new face of disease. Atherosclerosis. 2009;206:328-34. 
24. Onodera R, Teramukai S, Tanaka S, et al. Bone marrow mononuclear cells versus G-CSF-mobilized peripheral blood mononuclear cells for treatment of lower limb ASO: pooled analysis for long-term prognosis. Bone Marrow Transplant. 2011;46:278-84.

25. Huang PP, Yang XF, Li SZ, Wen JC, Zhang Y, Han ZC. Randomised comparison of G-CSF-mobilized peripheral blood mononuclear cells versus bone marrow-mononuclear cells for the treatment of patients with lower limb arteriosclerosis obliterans. Thromb Haemost. 2007;98:1335-42.

26. Matoba S, Tatsumi T, Murohara T, et al. Long-term clinical outcome after intramuscular implantation of bone marrow mononuclear cells (Therapeutic Angiogenesis by Cell Transplantation [TACT] trial) in patients with chronic limb ischemia. Am Heart J. 2008;156:1010-8.

27. Gupta PK, Krishna M, Chullikana A, et al. Administration of adult human bone marrow-derived, cultured, pooled, allogeneic mesenchymal stromal cells in critical limb ischemia due to Buerger's disease: phase II study report suggests clinical efficacy. Stem Cells Transl Med. 2017;6:689-99.

28. Liotta F, Annunziato F, Castellani S, et al. Therapeutic efficacy of autologous non-mobilized enriched circulating endothelial progenitors in patients with critical limb ischemia- the SCELTA trial. Circ J. 2018;82:1688-98.

29. Szabó GV, Kövesd Z, Cserepes J, Daróczy J, Belkin M, Acsády G. Peripheral blood-derived autologous stem cell therapy for the treatment of patients with late-stage peripheral artery disease-results of the short- and long-term follow-up. Cytotherapy. 2013;15:1245-52.

30. Kinoshita M, Fujita Y, Katayama M, et al. Long-term clinical outcome after intramuscular transplantation of granulocyte colony stimulating factormobilized CD34 positive cells in patients with critical limb ischemia. Atherosclerosis. 2012;224:440-5.

31. Heo SH, Park YS, Kang ES, et al. Early results of clinical application of autologous whole bone marrow stem cell transplantation for critical limb ischemia with Buerger's disease. Sci Rep. 2016;6:19690.

32. Kim SW, Han H, Chae GT, et al. Successful stem cell therapy using umbilical cord blood-derived multipotent stem cells for Buerger's disease and ischemic limb disease animal model. Stem Cells. 2006;24:1620-6.

33. Guo J, Guo L, Cui S, Tong Z, Dardik A, Gu Y. Autologous bone marrowderived mononuclear cell therapy in Chinese patients with critical limb ischemia due to thromboangiitis obliterans: 10-year results. Stem Cell Res Ther. 2018;9:43.

34. Horie $\mathrm{T}$, Onodera $\mathrm{R}$, Akamastu M, Ichikawa $\mathrm{Y}$, Hoshino J, Kaneko E, et al. Long-term clinical outcomes for patients with lower limb ischemia implanted with G-CSF-mobilized autologous peripheral blood mononuclear cells. Atherosclerosis. 2010;208:461-6.

35. Sprengers RW, Moll FL, Teraa M, Verhaar MC. Rationale and design of the JUVENTAS trial for repeated intra-arterial infusion of autologous bone marrow-derived mononuclear cells in patients with critical limb ischemia. J Vasc Surg. 2010;51:1564-8

36. Teraa M, Sprengers RW, Schutgens RE, et al. Effect of repetitive intra-arterial infusion of bone marrow mononuclear cells in patients with no-option limb ischemia: the randomized, double-blind, placebo-controlled rejuvenating endothelial progenitor cells via transcutaneous intra-arterial supplementation (JUVENTAS) trial. Circulation. 2015;131:851-60.

37. Pan $\mathrm{T}$, Liu H, Fang $Y$, et al. Predictors of responders to mononuclear stem cell-based therapeutic angiogenesis for no-option critical limb ischemia. Stem Cell Res Ther. 2019:10:15.

38. Benoit $\mathrm{E}, \mathrm{O}^{\prime}$ Donnell TF Jr, lafrati MD, et al. The role of amputation as an outcome measure in cellular therapy for critical limb ischemia: implications for clinical trial design. J Transl Med. 2011;9:165.

39. Walter $\mathrm{DH}$, Krankenberg $\mathrm{H}$, Balzer JO, et al. Intraarterial administration of bone marrow mononuclear cells in patients with critical limb ischemia: a randomized-start, placebo-controlled pilot trial (PROVASA). Circ Cardiovasc Interv. 2011;4:26-37.

40. Madaric J, Klepanec A, Valachovicova M, et al. Characteristics of responders to autologous bone marrow cell therapy for no-option critical limb ischemia. Stem Cell Res Ther. 2016;7:116.

41. Mills JL Sr, Conte MS, Armstrong DG, et al. The Society for Vascular Surgery Lower Extremity Threatened Limb Classification System: risk stratification based on wound, ischemia, and foot infection (WIfI). J Vasc Surg. 2014;59: 220-34.e1-2.

42. Amadesi $\mathrm{S}$, Reni $\mathrm{C}$, Katare $\mathrm{R}$, et al. Role for substance p-based nociceptive signaling in progenitor cell activation and angiogenesis during ischemia in mice and in human subjects. Circulation. 2012:125:1774-86 s1-19.
43. Barcelos LS, Duplaa C, Krankel N, et al. Human CD133+ progenitor cells promote the healing of diabetic ischemic ulcers by paracrine stimulation of angiogenesis and activation of Wnt signaling. Circ Res. 2009;104:1095-102.

44. Chen T, Chen D, Li F, Tan Z. Netrin-1 with stem cells promote angiogenesis in limb ischemic rats. J Surg Res. 2014;192:664-9.

45. Krankel N, Katare RG, Siragusa M, et al. Role of kinin B2 receptor signaling in the recruitment of circulating progenitor cells with neovascularization potential. Circ Res. 2008;103:1335-43.

46. Richart A, Loyer $X$, Neri $T$, et al. MicroRNA-21 coordinates human multipotent cardiovascular progenitors therapeutic potential. Stem Cells. 2014;32:2908-22.

47. Cho JG, Lee JH, Hong SH, et al. Tauroursodeoxycholic acid, a bile acid, promotes blood vessel repair by recruiting vasculogenic progenitor cells. Stem Cells. 2015;33:792-805

48. Benitez E, Sumpio BJ, Chin J, Sumpio BE. Contemporary assessment of foot perfusion in patients with critical limb ischemia. Semin Vasc Surg. 2014;27: $3-15$.

49. Fujita Y, Kinoshita M, Furukawa Y, et al. Phase II clinical trial of CD34+ cell therapy to explore endpoint selection and timing in patients with critical limb ischemia. Circ J. 2014:78:490-501.

\section{Publisher's Note}

Springer Nature remains neutral with regard to jurisdictional claims in published maps and institutional affiliations.
Ready to submit your research? Choose BMC and benefit from:

- fast, convenient online submission

- thorough peer review by experienced researchers in your field

- rapid publication on acceptance

- support for research data, including large and complex data types

- gold Open Access which fosters wider collaboration and increased citations

- maximum visibility for your research: over $100 \mathrm{M}$ website views per year

At $\mathrm{BMC}$, research is always in progress.

Learn more biomedcentral.com/submissions 